\title{
CARACTERIZAÇÃO E ESTUDO DA LIXIVIAÇÃO DE METAIS DE ESCÓRIAS PROVENIENTES DA RECICLAGEM DE BATERIAS DE CHUMBO-ÁCIDO
}

\author{
M. B. ANDRADE, W. COSTA* e A. V. C. ANDRADE \\ Universidade Estadual de Ponta Grossa (UEPG) \\ wcosta@uepg.br*
}

Artigo submetido em março/2014 e aceito em outubro/2014

DOI: $10.15628 /$ holos.2014.2042

\section{RESUMO}

No Brasil, o chumbo metálico é obtido principalmente a partir da reciclagem de baterias de chumbo-ácido utilizando o processo pirometalúrgico, que é acompanhado da geração de uma escória que apresenta elementos como $\mathrm{Fe}, \mathrm{Si}, \mathrm{S}, \mathrm{Al}, \mathrm{Ca}, \mathrm{Zn}, \mathrm{Pb}$. O objetivo deste trabalho foi de estudar a escória gerada no processo através da fluorescência e difração de raios $X$ e de extrações utilizando o método de Tessier seguida da determinação das concentrações dos metais nos extratos por espectrometria de absorção atômica. Com os resultados da fluorescência de raios $X$, observou-se que a somatória das porcentagens dos elementos citados se aproxima a $97 \%$. Pela difração de raios $X$, detectou-se fases como: Pirrotita $\left(\mathrm{Fe}_{1-x} \mathrm{~S}\right)$, Maghemita $\left(\mathrm{Fe}_{2} \mathrm{O}_{3}\right)$, Fayalita $\left(\mathrm{Fe}_{2}+2 \mathrm{SiO}_{4}\right)$, Óxido de chumbo e alumínio $\left(\mathrm{Pb}_{2} \mathrm{Al}_{2} \mathrm{O}_{5}\right)$, Hercinita $\left(\mathrm{Fe}_{2}+\mathrm{Al}_{2} \mathrm{O}_{4}\right)$ e Óxido de chumbo $\left(\mathrm{Pb}_{2} \mathrm{O}_{3}\right)$ e que nos extratos, estão presentes vários metais em concentrações variáveis, sendo que chumbo e ferro são encontrados geralmente em maior concentração.

PALAVRAS-CHAVE: baterias de chumbo, reciclagem de baterias, método de Tessier.

\section{CHARACTERIZATION AND STUDY OF LEACH METAL SLAG FROM THE RECYCLING LEAD ACID BATTERIES}

\begin{abstract}
In Brazil, the metallic lead is obtained mainly from recycled lead-acid batteries using the pyrometallurgical process, which is accompanied by the generation of a slag which features elements such as Fe, Si, S, Al, Ca, Zn, Pb. The objective of this work was to study the slag generated in this process by fluorescence and X-ray diffraction and extraction using the Tessier method followed by the determination of concentrations of metals in the extracts by atomic spectrometry. The results of X-ray
\end{abstract}

fluorescence, was observed that the sum of the percentages of the components mentioned approaches $97 \%$. For the X-ray diffraction, was detected phases as pyrrhotite $\left(\mathrm{Fe}_{1-\mathrm{x}} \mathrm{S}\right)$, maghemite $\left(\mathrm{Fe}_{2} \mathrm{O}_{3}\right)$, Fayalita $\left(\mathrm{Fe}_{2}+2 \mathrm{SiO}_{4}\right)$, lead and aluminum oxide $\left(\mathrm{Pb}_{2} \mathrm{Al}_{2} \mathrm{O}_{5}\right)$, Hercinita $\left(\mathrm{Fe}_{2}+\mathrm{Al}_{2} \mathrm{O}_{4}\right)$ and lead oxide $\left(\mathrm{Pb}_{2} \mathrm{O}_{3}\right)$ and in extracts, various metals are present in variable concentrations, and the lead and iron are usually found in higher concentration.

KEYWORDS: lead-acid batteries, battery recycling, Tessier method. 


\section{INTRODUÇÃO}

O chumbo, um elemento abundante na natureza, foi muito utilizado na antiguidade para revestir encanamentos de água, fabricar objetos de adorno, transportar e armazenar alimentos. Atualmente, pode ser encontrado em grande número de produtos como baterias, latão, bronze, radiadores, soldas, cabos, tintas e corantes, cerâmica, munição, gráfica (MINOZZO et al., 2008).

A produção de baterias chumbo-ácidas, representa o segmento industrial responsável pela maior utilização de chumbo (MATTE et al., 1989), sendo responsável por cerca de $70 \%$ do que é consumido mundialmente (PAOLIELLO, CHASIN, 2001).

Este dispositivo foi inventado por Planté em 1859 e consistia de duas tiras longas de chumbo, intermediadas por camadas de tecido grosso, sendo o conjunto imerso em uma solução a 10\% de ácido sulfúrico (MACHADO, 2002). Uma série de outras melhorias técnicas realizadas por outros investigadores levou à produção comercial de acumuladores chumbo-ácido (BASEL CONVENTION, 2003).

O chumbo utilizado pode ser classificado como primário (proveniente de minas) e secundário (obtido pelo refino do material reciclado). Um dos bens com maior índice de reciclagem no mundo é a bateria de chumbo; em nível mundial, o percentual de reciclagem de chumbo está em torno de $60 \%$. No setor específico de baterias automotivas este percentual aproxima-se de $95 \%$ e no Brasil fica entre 70 e 80\% (SILVA, 2001). Existem vários países, além do Brasil, que dependem exclusivamente da produção secundária deste metal (JOST, 2001).

As placas de uma bateria são constituídas de estruturas de chumbo metálico, cobertas por uma pasta de dióxido de chumbo (no caso das placas negativas) ou por uma pasta de chumbo metálico poroso (no caso das placas positivas). O chumbo usado em ambas às placas também contém uma série de outros elementos químicos, como antimônio, arsênio, bismuto, cádmio, cobre, cálcio, prata e estanho (BURGESS, 1995).

O método convencional de recuperação de chumbo utiliza o processo pirometalúrgico, que é realizado em fornos tipos cuba, revérberos, rotativos ou outros tipos de fornos que liberam gases como o $\mathrm{SO}_{x}$ e particulados de chumbo para a atmosfera, além de gerar borra metálica (FERRACINI, 2001).

Segundo MACHADO (2002), para que ocorra a redução da sucata metálica a chumbo metálico, são adicionados carbono e ferro como agentes redutores e todos os componentes são submetidos a altas temperaturas. As reações que ocorrem são representadas pelas equações 1,2 e 3 .

$$
\begin{aligned}
& \mathrm{PbO}_{(\mathrm{s})}+\mathrm{C}_{(\mathrm{s})} \rightarrow \mathrm{Pb}_{(\mathrm{s})}^{0}+\mathrm{CO}_{(\mathrm{g})} \quad \text { equação (1) } \\
& \mathrm{PbO}_{2(\mathrm{~s})}+2 \mathrm{CO}_{(\mathrm{g})} \rightarrow \mathrm{Pb}_{(\mathrm{s})}+2 \mathrm{CO}_{2(\mathrm{~g})} \text { equação (2) } \\
& \mathrm{PbSO}_{4(s)}+\mathrm{Fe}_{(\mathrm{s})}^{0} \rightarrow \mathrm{Pb}_{(s)}^{0}+\mathrm{FeSO}_{4(s)} \text { equação (3) }
\end{aligned}
$$

Além do chumbo, ocorre a geração de uma escória cuja quantidade corresponde a $25 \%$ da quantidade de chumbo produzida (FERRACIN, 2001) e que é constituída aparentemente por $\mathrm{FeSO}_{4}, \mathrm{PbSO}_{4}, \mathrm{PbO}$ não convertido e todo o tipo de impurezas que tenham sido introduzidas no forno juntamente com o material a ser reciclado e seus aditivos. 
A contribuição deste estudo reside na avaliação química de escória proveniente da reciclagem de chumbo que utiliza processo pirometalúrgico, as caracterizações estruturais que indicam por sua vez as formas de associação do metal e o potencial de mobilização de metais a partir de método de Tessier e colaboradores (1979).

\section{METODOLOGIA}

Foram estudadas as escórias denominadas inicial, secundária e final. A inicial e secundária acompanham respectivamente a primeira e a segunda porção do chumbo retirado do forno. A final é gerada no processo de limpeza do forno.

Tomou-se porções destas escórias, que foram trituradas em almofariz e pistilo de ágata e peneiradas em malha de 0,105 $\mathrm{mm}$ de abertura da malha para serem submetidas a caracterização química, determinação estrutural e avaliação da mobilidade. A caracterização química foi realizada por fluorescência de raios $X$, a determinação estrutural por difração de raios $X$ e para a avaliação da mobilização de metais, eles foram lixiviados e suas concentrações foram determinadas por espectrometria de absorção atômica.

\subsection{Fluorescência de raios $X$}

Utilizou-se o espectrômetro de Flurescência de raios $X$ e energia dispersiva da marca Shimadzu (EDX-720), operado a $50 \mathrm{kV}$, alvo de Rh, $10 \mathrm{~mA}$, Collimator: $10 \mathrm{~mm}$, Detector: Si(Li) semiconductor detector, resolução de energia em aproximadamente $155 \mathrm{eV}$ e tempo de análise de $100 \mathrm{~s}$.

\subsection{Difração de raios $X$}

Os dados foram coletados no equipamento da marca Rigaku, modelo Rint-2000, com anodo rotatório de cobre operando a $42 \mathrm{kV}$ e $120 \mathrm{~mA}$, modo de varredura passo-a-passo com passos de $0,02^{\circ}$ e tempo por passo igual a $2 \mathrm{~s}$, no alcance de $5^{\circ}$ a $90^{\circ}$. As fases cristalinas foram identificadas com auxílio de software de busca por comparação das fichas JCPDS com os padrões de difração.

\subsection{Avaliação da mobilidade de metais (Espectrometria de absorção atômica de chama)}

Para a avaliação da mobilidade dos metais, foi realizada a extração sequencial nas amostras das escórias, segundo método de Tessier e colaboradores (1979), conduzidas em quadruplicata para $1 \mathrm{~g}$ de cada amostra (inicial, secundária e final). As soluções empregadas são de reagentes seletivos, isto é, capazes de extrair para a fase líquida os elementos presentes em tipos específicos de fases, ou frações, por reações de dupla troca iônica, oxi-redução e dissolução (BOSSO, ENZWEILER, 2008).

Nesta extração os metais lixiviados estão nas formas em podem ser removidos em $\mathrm{pH}=8,0$; $\mathrm{pH}=5,0$; aplicação de um redutor $(\mathrm{R})$ e oxidante $(\mathrm{O})$. A forma residual $(\mathrm{R})$ é obtida quando a amostra recebe um tratamento agressivo com ácidos fluorídrico e perclórico.

As concentrações dos metais $\mathrm{Cr}, \mathrm{Cu}, \mathrm{Ni}, \mathrm{Fe}, \mathrm{Mn}, \mathrm{Zn}$ e $\mathrm{Pb}$ nos lixiviados foram determinadas por espectroscopia de absorção atômica com atomização por chama utilizando o aparelho Varian Spectra AAS - 240FS. 


\section{RESULTADOS E DISCUSSÃO}

\subsection{Fluorescência de raios $X$}

$\mathrm{Na}$ tabela 01, se encontram as composições químicas das diferentes partes da escória determinadas por fluorescência de raios $\mathrm{X}$ pelo método de análise semi-quantitativa, expressos em porcentagem, normalizados para $100 \%$

\begin{tabular}{|c|c|c|c|}
\hline Elemento & Inicial (\%) & Secundária (\%) & Final (\%) \\
\hline $\mathrm{Fe}$ & 64,5 & 68,8 & 72,0 \\
\hline $\mathrm{Si}$ & 11,1 & 9,8 & 5,1 \\
\hline S & 6,1 & 7,2 & 7,1 \\
\hline Al & 6,0 & 4,1 & 2,8 \\
\hline $\mathrm{Ca}$ & 4,0 & 4,3 & 1,7 \\
\hline $\mathrm{Pb}$ & 3,2 & 2,7 & 8,6 \\
\hline $\mathrm{Zn}$ & 1,3 & 0,6 & 0,6 \\
\hline $\mathrm{Ba}$ & 0,9 & - & - \\
\hline $\mathrm{Mn}$ & 0,8 & 0,5 & 0,4 \\
\hline $\mathrm{Ti}$ & 0,8 & 1,0 & 0,7 \\
\hline K & 0,6 & 0,6 & 0,2 \\
\hline $\mathrm{Cr}$ & 0,3 & 0,2 & 0,1 \\
\hline $\mathrm{Ra}$ & 0,1 & 0,1 & 0,3 \\
\hline Sn & 0,1 & - & - \\
\hline $\mathrm{Cu}$ & 0,1 & 0,1 & 0,3 \\
\hline $\mathrm{Zr}$ & 0,1 & - & - \\
\hline 1 & - & - & 0,1 \\
\hline
\end{tabular}

Observou-se que os elementos mais representativos são $\mathrm{Fe}, \mathrm{Si}, \mathrm{S}, \mathrm{Al}, \mathrm{Ca}, \mathrm{Pb}$ e $\mathrm{Zn}$, que estão em concentrações geralmente maiores que as encontrados por KREUCH (2005). A soma destes elementos representa aproximadamente $97 \%$ da massa total das escórias. A somatória das concentrações dos demais elementos presentes ( $\mathrm{Ba}, \mathrm{Mn}, \mathrm{Ti}, \mathrm{K}, \mathrm{Cr}, \mathrm{Ra}, \mathrm{Sn}, \mathrm{Cu}, \mathrm{Zr}, \mathrm{I}$ ), corrresponde a aproximadamente $3 \%$. O elemento que está em maior concentração é o ferro $(64,5-72,0 \%)$, que é acrescentado objetivando a redução do $\mathrm{PbSO}_{4}$ (equação 3). Enxofre (6,1 a 7,2 \%), cuja origem principal é a reação 3 e os elementos: silício $(5,1$ a $11,1 \%)$, alumínio $(2,8$ a 6,0 \%) e cálcio $(1,7$ a 4,3 \%), que possivelmente são oriundos do carvão, também estão em quantidades significativas.

A presença de chumbo nas amostras demonstra que está ocorrendo a retenção deste metal na escória; o que parece ser um evento comum (CHACÓN-SANHUEZA, FONTANETTI, 2006; CARVALHO et al., 2003; KREUSCH, 2005). Os teores encontrados foram geralmente maiores que aqueles presentes nos trabalhos citados neste parágrafo, sendo igual a 3,2 \% para a escória inicial, 2,7 \% para escória secundária e 8,6 \% para a escória final. Dos elementos mais tóxicos, além do chumbo, foram também encontrados em todas as amostras, zinco, manganês, cromo e cobre.

\subsection{Difração de raios $X$}

A caracterização estrutural das diferentes partes da escória foi determinada por difração de raios $X$. Os difratogramas estão apresentados nas figuras 1, 2 e 3 e apresentam uma composição mineralógica complexa. Além da presença de fase amorfa, é possível observar picos de difração 
característicos das fases cristalinas existentes. Os picos não identificados se devem a elevada sobreposição provocada pela presença das várias fases cristalinas.

A figura 1 representa o difratograma para a amostra inicial. Na amostra estudada, as principais fases encontradas foram: Pirrotita $\left(\mathrm{Fe}_{1}-\mathrm{xS}\right)$, Maghemita $\left(\mathrm{Fe}_{2} \mathrm{O}_{3}\right)$, Fayalita $\left(\mathrm{Fe}_{2}+2 \mathrm{SiO}_{4}\right)$, Óxido de chumbo e alumínio $\left(\mathrm{Pb}_{2} \mathrm{Al}_{2} \mathrm{O}_{5}\right)$, Hercinita $\left(\mathrm{Fe}_{2}+\mathrm{Al}_{2} \mathrm{O}_{4}\right)$ e Óxido de chumbo $\left(\mathrm{Pb}_{2} \mathrm{O}_{3}\right)$.

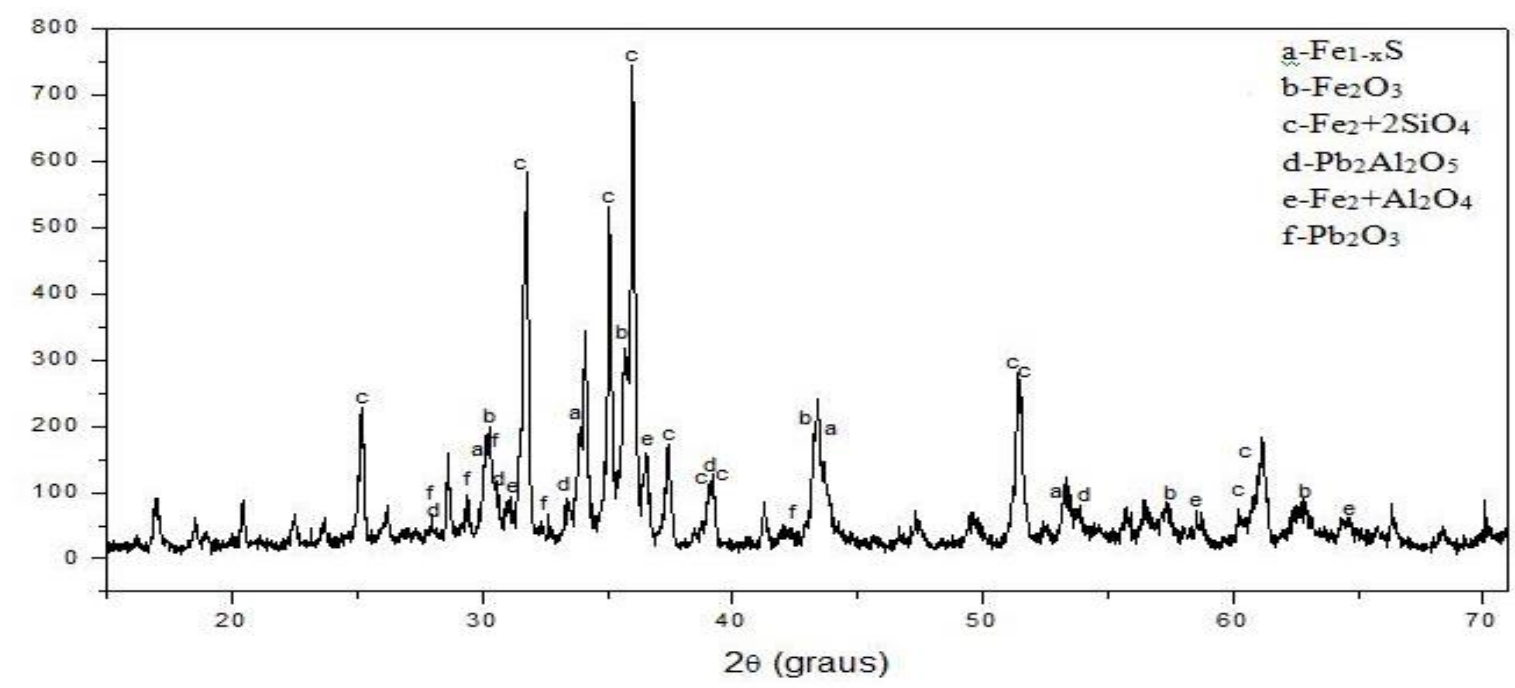

Figura 1: Difratograma de raios $X$ da amostra inicial

A figura 2 representa o difratograma da amostra secundária. Na amostra estudada, as principais fases encontradas foram: chumbo metálico $(\mathrm{Pb})$, Wuestita $\left(\mathrm{Fe}_{0.9712} \mathrm{O}\right)$, Sulfeto de ferro $\left(\mathrm{Fe}_{0,975} \mathrm{~S}\right)$, Fayalita $\left(\mathrm{Fe}_{2}+2 \mathrm{SiO}_{4}\right)$, Maghemita $\left(\mathrm{Fe}_{2} \mathrm{O}_{3}\right)$ e Hercinita $\left(\mathrm{Fe}_{2}+\mathrm{Al}_{2} \mathrm{O}_{4}\right)$.

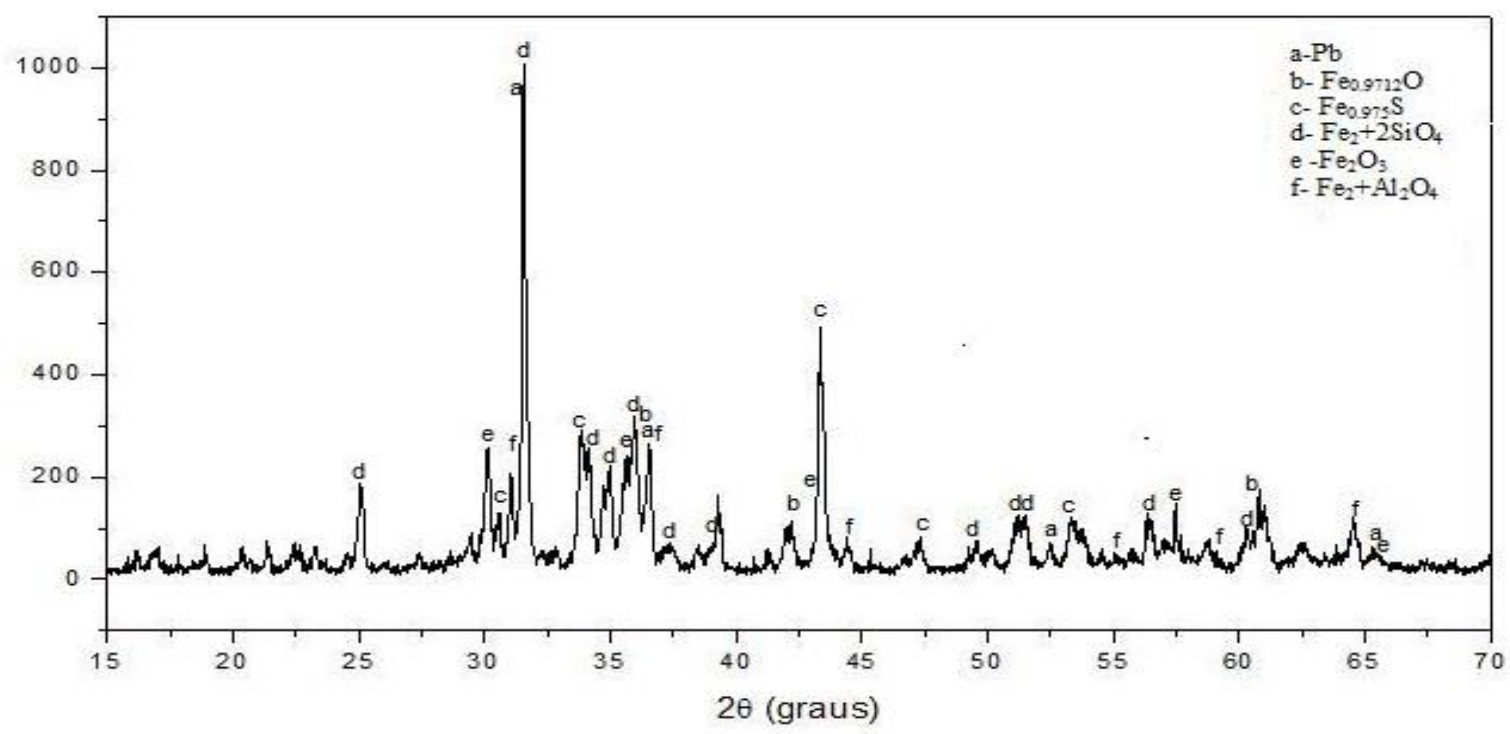

Figura 2: Difratograma de raios $X$ da amostra secundária

A figura 3 representa o difratograma da amostra final. Na amostra estudada, as principais fases encontradas foram: Pistita $\left(\mathrm{Fe}_{0,909} \mathrm{O}\right)$, Pistita sim. $\left(\mathrm{Fe}_{0,916} \mathrm{O}\right)$, Sulfeto de chumbo $(\mathrm{PbS})$, Óxido de Ferro $\left(\mathrm{Fe}_{3} \mathrm{O}_{4}\right)$, Sulfeto de chumbo (PbS), Wuestita ( $\left.\mathrm{Fe}_{9712} \mathrm{O}\right)$, Sulfeto de ferro $\left(\mathrm{Fe}_{105} \mathrm{~S}_{0,95}\right)$, Magnetita $\left(\mathrm{Fe}_{3} \mathrm{O}_{4}\right)$, Pirrotita $\left(\mathrm{Fe}_{1-\mathrm{x}} \mathrm{S}\right)$, Silicato de cálcio e alumínio $\left(\mathrm{Ca}_{2} \mathrm{Al}_{2} \mathrm{SiO}_{7}\right)$, Fayalita $\left(\mathrm{Fe}_{2}+2 \mathrm{SiO}_{4}\right)$, Maghemita $\left(\mathrm{Fe}_{2} \mathrm{O}_{3}\right)$ e Hercinita $\left(\mathrm{Fe}_{2}+\mathrm{Al}_{2} \mathrm{O}_{4}\right)$. 


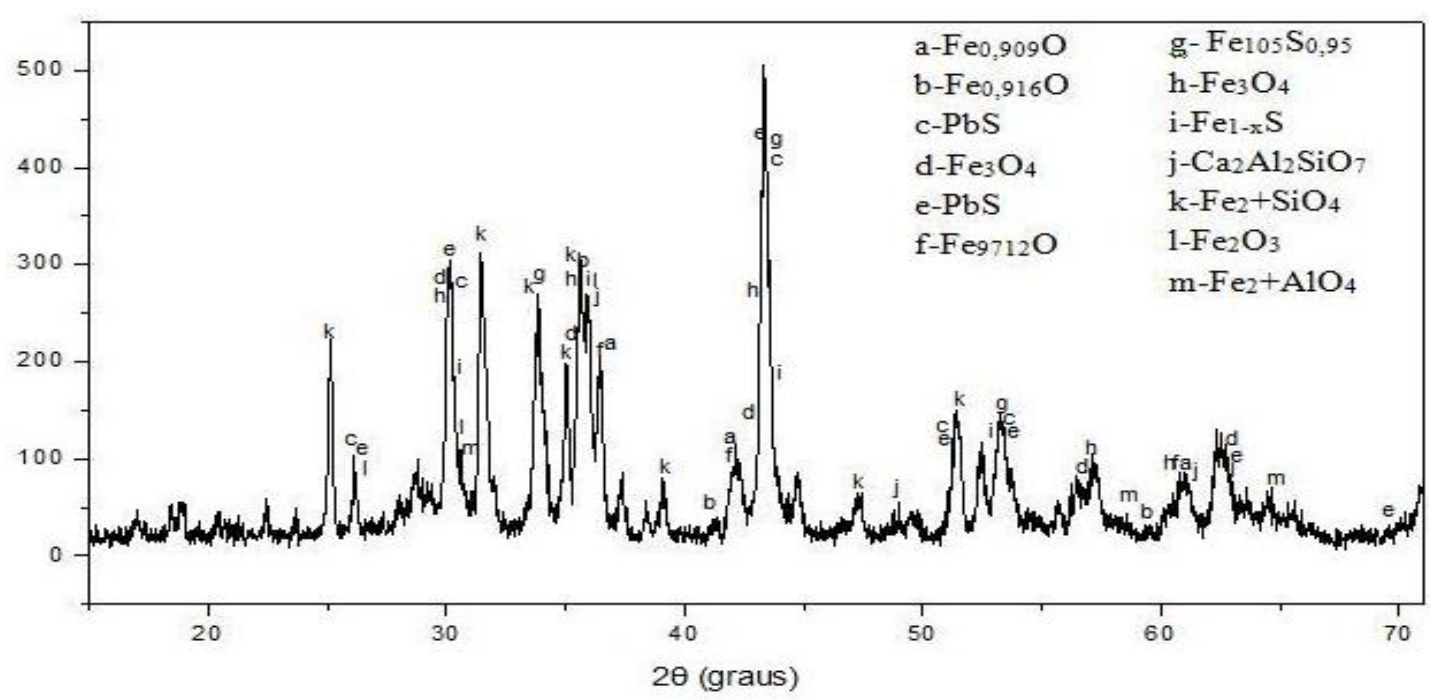

Figura 3: Difratograma de raios $X$ da amostra final

Na escória inicial e secundária, o maior pico é da Fayalita, que é a forma predominante do ferro nestas amostras. Na escória final, a Fayalita é encontrada, mas os maiores picos são de sulfeto de chumbo e sulfeto de ferro. A Maghemita é encontrada em todas as amostras da escória assim como alguns outros óxidos e sulfetos de ferro e óxidos e sulfetos de chumbo não estequiométricos. Nos difratogramas das três amostras não foram encontrados picos de difração referentes ao $\mathrm{FeSO}_{4}$ que é gerado na reação 3 .

\subsection{Avaliação da mobilidade de metais}

O método de Tessier (TESSIER et al., 1979) foi criado para a determinação de metais pesados em sedimentos (LÃ et al., 2003). Nesta avaliação, o interesse está focado nas condições variáveis de $\mathrm{pH}$ e de oxidação/redução que permitem a lixiviação de metais e assim avaliar os possíveis danos ambientais quando da disposição inadequada das escórias.

Na contaminação ambiental, a exposição do material a determinadas condições permite a formação de lixiviados, cujas concentrações de metais podem ser comparadas com as de efluentes que podem ser lançados, direto ou indiretamente nos cursos d'água. A Resolução CONAMA 430/11 traz os valores máximos permitidos (VMP) das condições padrões de lançamento de efluentes. Quando os valores são encontrados acima do VMP, este percolado possui potencial para causar efeitos tóxicos ao ambiente.

TABELA 02 - Concentrações médias de metais em $\mathrm{mg} \mathrm{L}^{-1}$ encontradas nas frações lixiviadas em $\mathrm{pH}=8,0$ e $\mathrm{pH}=5,0$; aplicação de um redutor (Red) e oxidante (O); fração residual (R) e soma das frações (S) na amostra inicial e o VMP de acordo com a Resolução CONAMA 430/11.

\begin{tabular}{lccccccc}
\hline \multirow{2}{*}{ Elementos } & \multicolumn{7}{c}{ Frações $\mathrm{mg} \mathrm{L}^{-1}$} \\
\cline { 2 - 8 } & $\mathrm{pH}=8,0$ & $\mathrm{pH}=5,0$ & Red & $\mathrm{O}$ & $\mathrm{R}$ & $\mathrm{S}$ & $\mathrm{VMP}$ \\
\hline Cromo & 0,0 & 0,0 & 0,3 & 0,0 & 25,8 & 26,1 & $\mathrm{Cr}^{6+} 0,1$ \\
Cobre & 0,2 & 0,3 & 0,1 & 7,0 & 4,4 & 12,0 & 1,0 \\
Níquel & 0,1 & 1,0 & 1,1 & 0,4 & 2,9 & 5,5 & 2,0 \\
Ferro & 0,0 & 1605,7 & 3392,0 & 124,7 & 3201,2 & 8323,6 & 15,0 \\
Manganês & 0,1 & 31,4 & 63,3 & 19,2 & 19,4 & 133,1 & 1,0 \\
Zinco & 0,3 & 46,0 & 61,4 & 25,9 & 62,2 & 195,8 & 5,0 \\
Chumbo & 25,2 & 623,4 & 150,7 & 15,8 & 32,6 & 847,7 & 0,5 \\
\hline
\end{tabular}


Analisando os dados presentes na Tabela 2, se observa que nos lixiviados da amostra inicial, as concentrações de níquel (residual), cromo (residual e com aplicação de um redutor) cobre (residual e aplicação de oxidante), ferro, manganês e zinco (residual, e aplicação de oxidante, redutor e $\mathrm{pH}=5,0)$, e chumbo (todas as frações), estão acima do VMP segundo a Resolução CONAMA 430/11. Destas, a fração residual não é preocupante, pois a remoção dos metais só ocorre com a utilização dos ácidos fluorídrico e perclórico em ebulição, condições estas, indisponíveis no meio ambiente.

Maiores preocupações são justificadas em relação as frações lixiviadas em condições presentes no meio ambiente como, presença de oxidantes, redutores e pHs iguais a 5,0 e 8,0. Tais condições permitirão com que o cobre, ferro, manganês, zinco e chumbo, sejam lixiviados em concentrações acima do VMP (CONAMA 430/11).

TABELA 03 - Concentrações médias de metais em $\mathrm{mg} \mathrm{L}^{-1}$ encontradas nas frações lixiviadas em $\mathrm{pH}=8,0$ e pH=5,0; aplicação de um redutor (Red) e oxidante (O); fração residual (R) e soma das frações (S) na amostra secundária e o VMP de acordo com a Resolução CONAMA 430/11.

\begin{tabular}{lccccccc}
\hline \multirow{2}{*}{ Elementos } & \multicolumn{7}{c}{ Frações $\mathrm{mg} \mathrm{L}^{-1}$} \\
\cline { 2 - 8 } & $\mathrm{pH}=8,0$ & $\mathrm{pH}=5,0$ & $\mathrm{Red}$ & $\mathrm{O}$ & $\mathrm{R}$ & $\mathrm{S}$ & $\mathrm{VMP}$ \\
\hline Cromo & 0,1 & 0,0 & 0,2 & 0,0 & 34,8 & 35,1 & $\mathrm{Cr}^{6+} 0,1$ \\
Cobre & 0,2 & 0,3 & 0,2 & 0,3 & 6,6 & 7,6 & 1,0 \\
Níquel & 0,1 & 1,3 & 1,0 & 0,0 & 6,1 & 8,5 & 2,0 \\
Ferro & 0,0 & 1203 & 2129 & 29,6 & 4547,9 & 7909,5 & 15,0 \\
Manganês & 0,1 & 18,3 & 35,7 & 23,7 & 21,3 & 99,1 & 1,0 \\
Zinco & 0,2 & 23,1 & 19,9 & 10,5 & 45,0 & 98,7 & 5,0 \\
Chumbo & 18,8 & 400 & 32,9 & 1,4 & 7,9 & 461 & 0,5 \\
\hline
\end{tabular}

Analisando os dados presentes na tabela 3, se observa que o comportamento dos metais da amostra secundária em relação à lixiviação e os problemas que isso pode acarretar, é o mesmo daqueles presentes na amostra inicial, excetuando o cobre, que nesta amostra está em concentrações acima VMP apenas na fração residual.

TABELA 04 - Concentrações médias de metais em $\mathrm{mg} \mathrm{L}^{-1}$ encontradas nas frações lixiviadas em $\mathrm{pH}=8,0$ e $\mathrm{pH}=5,0$; aplicação de um redutor (Red) e oxidante (O); fração residual (R) e soma das frações (S) na amostra final e o VMP de acordo com a Resolução CONAMA 430/11.

\begin{tabular}{lccccccc}
\hline \multirow{2}{*}{ Elementos } & \multicolumn{7}{c}{ Frações $\mathrm{mg} \mathrm{L}^{-1}$} \\
\cline { 2 - 8 } & $\mathrm{pH}=8,0$ & $\mathrm{pH}=5,0$ & Red & $\mathrm{O}$ & $\mathrm{R}$ & $\mathrm{S}$ & $\mathrm{VMP}$ \\
\hline Cromo & 0,0 & 0,0 & 0,3 & 0,0 & 18,8 & 19,1 & $\mathrm{Cr}^{6+} 0,1$ \\
Cobre & 0,2 & 0,3 & 0,2 & 10,1 & 40,8 & 51,6 & 1,0 \\
Níquel & 0,1 & 2,3 & 3,9 & 0,4 & 3,4 & 10,1 & 2,0 \\
Ferro & 0,0 & 2150 & 3428 & 6,0 & 6452 & 12036 & 15,0 \\
Manganês & 0,1 & 24,4 & 21,8 & 4,2 & 8,1 & 58,6 & 1,0 \\
Zinco & 0,3 & 20,6 & 22,0 & 21,2 & 34,5 & 98,6 & 5,0 \\
Chumbo & 114,1 & 2515,3 & 532,4 & 53,5 & 130,4 & 3345,7 & 0,5 \\
\hline
\end{tabular}

Analisando os dados presentes na tabela 4, se observa que o comportamento dos metais da amostra final em relação à lixiviação e os problemas que isso pode acarretar, é o mesmo daqueles presentes na amostra inicial, excetuando o níquel, que nessa amostra estão em concentrações acima VMP também nas frações lixiviadas pela presença de um redutor e pH igual a 5,0 . 


\subsection{Distribuição dos metais nas diversas frações}

As figuras 4, 5 e 6 trazem as distribuições das concentrações dos metais nas diversas frações.

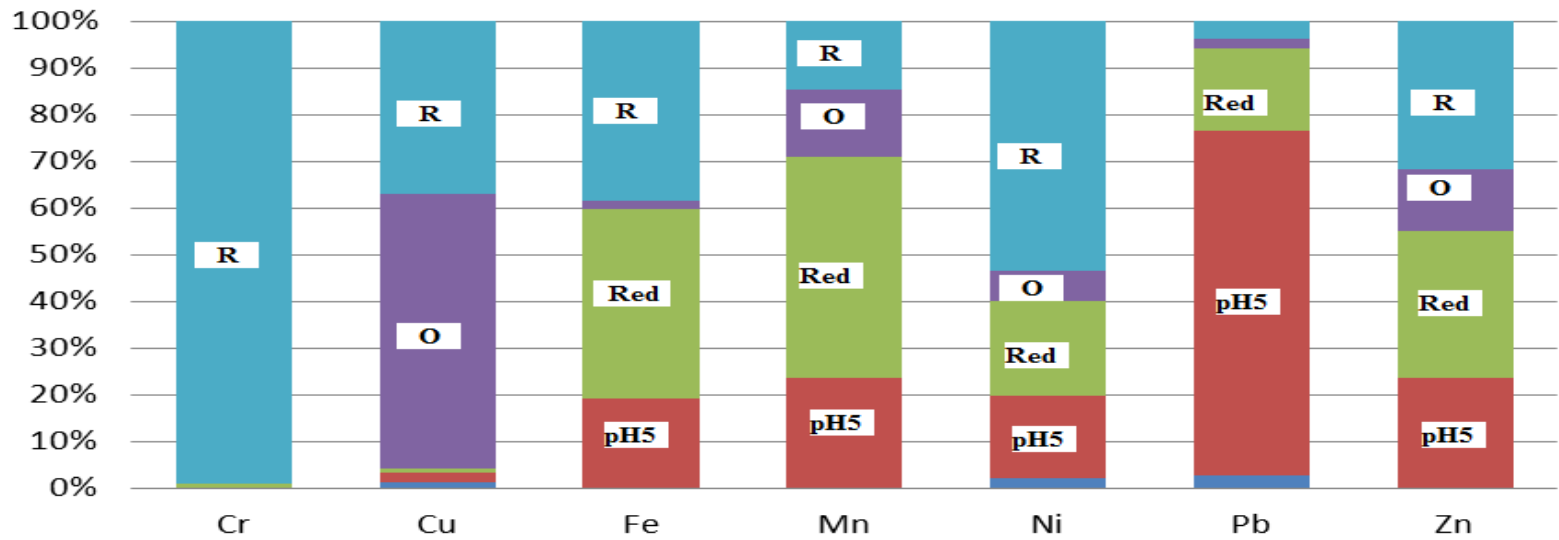

Figura 4: Distribuição das concentrações de cromo, cobre, ferro, manganês, níquel, chumbo e zinco nas frações lixiviadas em $\mathrm{pH}=8,0$ e $\mathrm{pH}=5,0$; aplicação de um redutor (Red) e oxidante $(0)$ e fração residual (R) da amostra inicial.

Pela análise dos dados presentes na figura 4, se observa que na amostra inicial, o cromo está basicamente na fração residual. $\mathrm{O}$ cobre se concentra principalmente na fração residual e lixiviável em presença de um oxidante. Para ferro, níquel, manganês e zinco predominam as frações residual e lixiviáveis em presença de um redutor e em pH igual a 5,0 mas, zinco, manganês e níquel apresentam também uma concentração destacada na fração lixiviável em presença de um oxidante. $O$ chumbo se concentra principalmente nas frações lixiviadas em pH igual a 5,0 e em presença de um redutor.

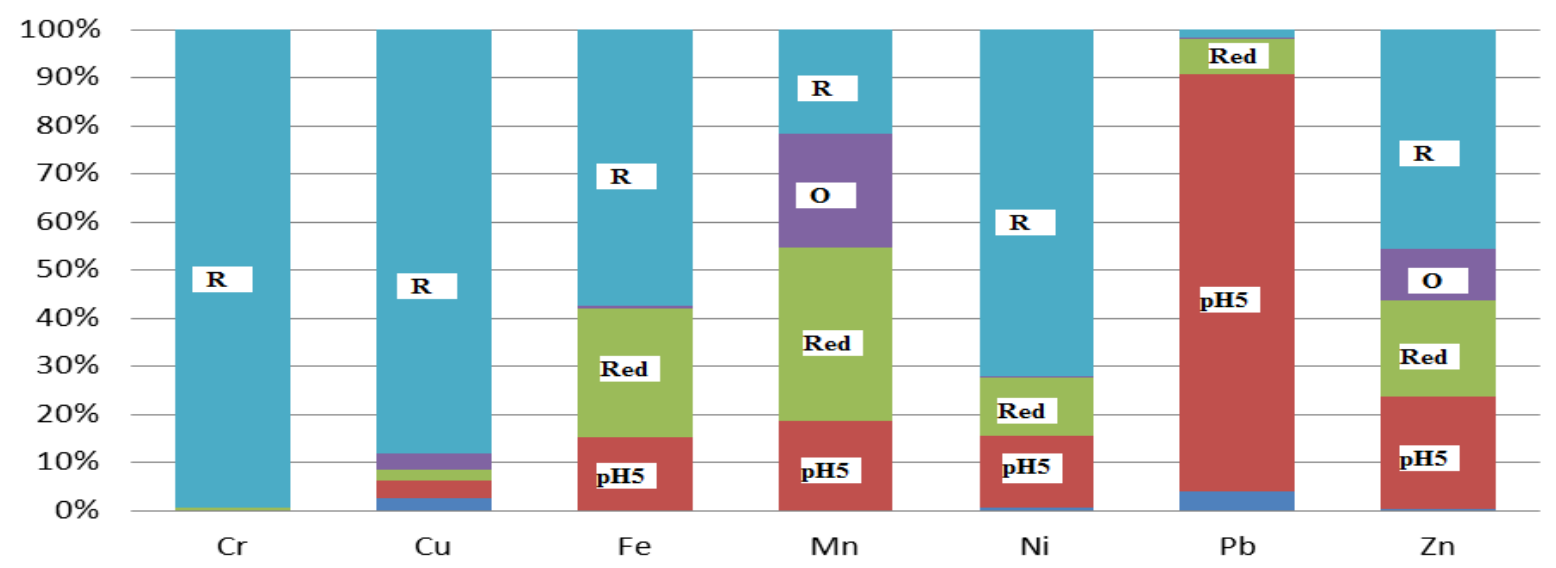

Figura 5: Distribuição das concentrações de cromo, cobre, ferro, manganês níquel, chumbo e zinco nas frações lixiviadas em $\mathrm{pH}=8,0$ e $\mathrm{pH}=5,0$; aplicação de um redutor (Red) e oxidante $(0)$ e fração residual $(\mathrm{R})$ da amostra sedundária.

Pela análise dos dados presentes na figura 5 , se observa que na amostra secundária, o cromo e o cobre estão basicamente na fração residual. Ferro, níquel, manganês e zinco estão distribuídos principalmente na fração residual e lixiviável em presença de redutor e $\mathrm{pH}$ igual a 5,0 mas, zinco e manganês apresentam também uma concentração destacada na fração lixiviável em 
presença de um oxidante. $O$ chumbo também se concentra principalmente nas frações lixiviáveis em pH igual a 5,0 e via ação de um redutor.

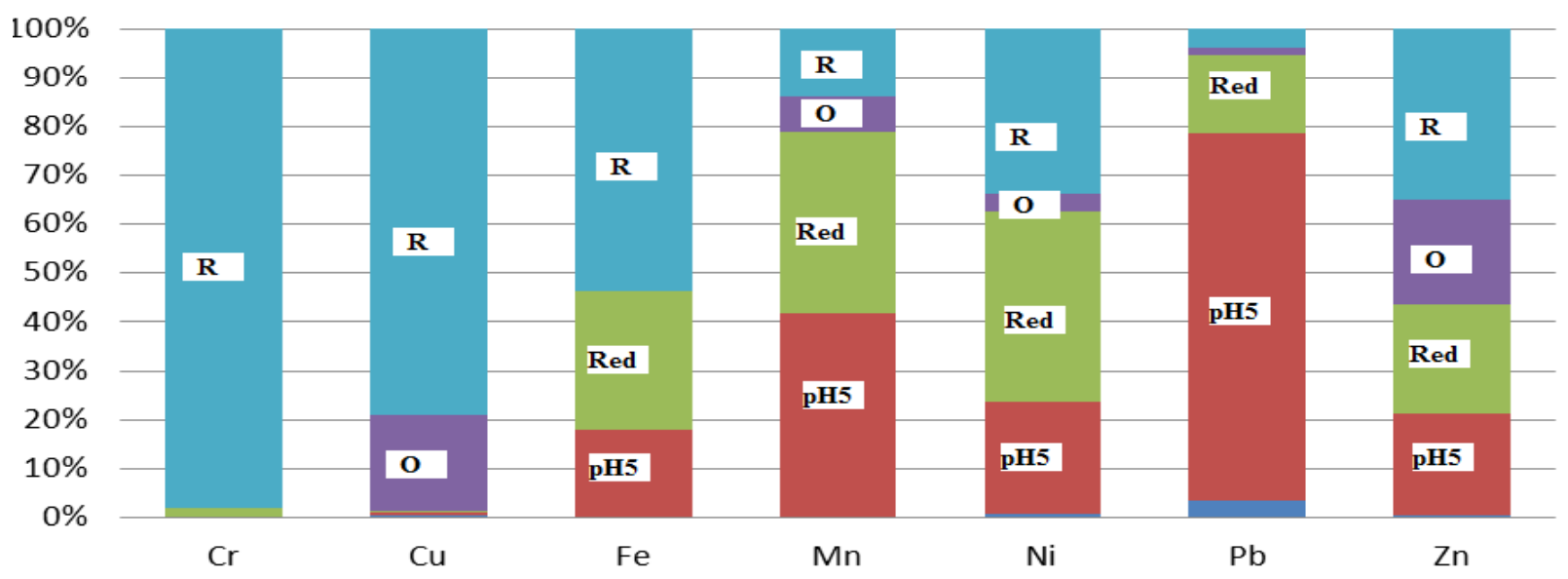

Figura 6: Distribuição das concentrações de cromo, cobre, ferro, manganês níquel, chumbo e zinco nas frações lixiviadas em $\mathrm{pH}=8,0$ e $\mathrm{pH}=5,0$ aplicação de um redutor (Red) e oxidante $(0)$ e fração residual (R) da amostra final.

Pela análise dos dados presentes na figura 6, se observa que na amostra final, o cromo está basicamente na fração residual. O cobre se concentra principalmente na fração residual, mas uma certa porção é encontrada na fração lixiviável via ação de um oxidante. Ferro, níquel, manganês e zinco estão distribuídos principalmente na fração residual e nas frações lixiviáveis via ação de um redutor e pH igual a 5,0 mas zinco e manganês e níquel apresentam também uma concentração considerável na fração lixiviável via ação de um oxidante. O chumbo se concentra principalmente nas frações lixiviáveis em pH igual a 5,0 e sob ação de um meio redutor.

Comparando as três amostras em relação às condições de lixiviação, se observa que existe uma grande semelhança entre elas. Diferenças ocorrem para o cobre, onde na amostra secundária a quantidade lixiviada em presença de um oxidante é pequena e para o níquel, onde na mesma amostra, diferentemente das amostras inicial e final, não é possível identificar a presença da porção lixiviada através do uso de um oxidante (figura 5).

Utilizando o mesmo método de extração (TESSIER et al., 1979) em outros materiais, Chitolina e colaboradores (2012), encontraram no decorrer de processos de compostagem de resíduos sólidos domiciliares, distribuição semelhante nas diversas fases para os metais: níquel, manganês, níquel e zinco.

Para o cobre, nas escórias ele foi encontrado principlamente na fração residual e lixiviável via ação de um oxidante, enquando que no resíduo da compostagem é lixiviável apenas via ação de um oxidante. Já o chumbo, nas escórias, está ligado principalmente à fração lixiviável em pH igual 5 e via ação de um redutor. No resíduo da compostagem, está distribuído de maneira semelhante nas fases residual e lixiviável em pH igual a 5 e sob ação de oxidante e redutor.

O ferro, em amostras de solo (LÃ et al., 2003) e em amostras de alginatos (LOS et al., 2013) foi encontrado principalmente na forma residual. Em amostras de lodo, Koumrouyan e Santana (2008), encontraram-no principalmente na forma lixiviável em pH igual a 8. Nas escórias, apesar da predominância da fração residual, o ferro também encontrado de maneira substancial na forma lixiviável em pH igual a 5 e sob ação de um redutor. 


\section{CONCLUSÕES}

Por meio da fluorescência de raios $X$ determinou-se os elementos presentes nas amostras inicial, secundária e final. A somatória das concentrações de ferro, silício, enxofre, alumínio, cálcio, chumbo e zinco atingiram valores próximos a $97 \%$ em massa dos elementos presentes, enquanto que a somatória das concentrações dos demais elementos, isto é: bário, manganes, tiânio, potássio, cromo, radônio, estanho, cobre, zircônio e iodo totalizaram aproximadamente 3 \%. Pela difração de raios $X$ obteve-se as principais formas em que os elementos estão associados. A fayalita é a forma predominante do ferro nas amostras inicial e secundária, pela presença do pico de maior intensidade. Já na amostra final, sulfeto de chumbo e de ferro são as formas predominantes, mas também há a presença de fayalita. A sobreposição dos picos dificulta a visualização das fases, portanto não é correto afirmar que algumas das fases não possam estar presentes em outras partes da escória. Podem estar presentes, porém em menor concentração. A avaliação da mobilização e disponibilidade dos metais a partir do método de Tessier e a comparação com os VMP do CONAMA 430/11 demonstra os riscos potenciais lixiviação desses metais. Excetuando o chumbo, as concentrações dos metais lixiviados em $\mathrm{pH}=8,0$ estão abaixo do VMP estabelecido pela legislação. Ferro, manganês, zinco, chumbo são lixiviados em concentrações bem acima que o VMP quando submetidos a $\mathrm{pH}=5,0$ ou sob ação de um redutor. Em presença de um oxidante, além de ferro, manganês, zinco e chumbo, ocorre geralmente à lixiviação de cobre em concentrações acima do VMP. Na fração residual, as concentrações de todos os metais estão acima do VMP. 0 cromo está predominantemente na fração residual. O cobre está geralmente na fração residual e na lixiviável em presença de um oxidante. Ferro, manganês, níquel e zinco estão concentrados nas frações residual e lixiviável em presença de redutor e $\mathrm{pH}=5,0$. Manganês, zinco e níquel, apresentam também uma concentração considerável na fração lixiviável em presença de um oxidante. $\mathrm{O}$ chumbo é lixiviável principalmente em $\mathrm{pH}=5,0$ e em presença de um redutor.

\section{REFERÊNCIAS}

1. BASEL CONVENTION. Technical Guidelines for the Environmentally Sound Management of Waste Lead-acid Batteries. Basel Convention series/SBC n. 2003/9.

2. BOSSO, S.T., ENZWEILER, J. Ensaios para determinar a (bio) disponibilidade de chumbo em solos contaminados: revisão. Química Nova, v.31, n. 2, p.394-400, 2008.

3. BRASIL, CONSELHO NACIONAL DO MENIO AMBIENTE- Resolução CONAMA, 430/2011. Disponível em:<http://www.mma.gov.br/port/conama/legiabre.cfm?codlegi=646. Acesso em: 15 de ago. 2012.

4. BURGESS, W.A. Recognition of health hazards in industry: a review of materials and processes. 2. Ed. New York: John Wiley \& Sons, 1995. 537p.

5. CARVAHO, M.F., SILVANY NETO, A. M., TAVARES, T.M., COSTA, A.C.A., CHAVES, C. d'El R., NASCIMENTO, L.D., REIS, M. de A. Chumbo no sangue de crianças e passivo ambiental de uma fundição de chumbo no Brasil. Revista Panamericana de Salud Pública, v.13, n.1, p.19-23, 2003.

6. CHITOLINA, J.C., Da SILVA, F.C., BARBIERI, V., PODSCLAN, S.B. Extração sequencial e especiação de matais pesados no decorrer do processo de compostagem de resíduos sólidos domiciliares. HOLOS Environment, v.12, n.1, p.99-106, 2012. 
7. CHACÓN-SANHUEZA, A.E. FONTANETTI, A.R. Novos processos de reciclagem de chumbo. Revista Matéria, v.11, n. 2, p.146-154, 2006.

8. FERRACIN, L.C., Desenvolvimento de Processo de Produção de Chumbo Eletrolítico a Partir de Sucata de Baterias Automotivas", Projeto RHAE / CNPq, Processo Institucional n.610044/98-2, 2001.

9. JOST, M., Technical Guidelines for the Environmentally Sound Management of Lead-acid Battery Wastes, 2001.

10. KOUMROUYAN, A., SANTANA, G.P. Química de elementos-traço nos sedimentos do Lago Parú (Manacapuru - Amazonas), sob influência do pulso de inundação do baixo Rio Solimões. Acta Amazonica, v.38, n.3, 491-501, 2008.

11. KREUSCH, M. A., Avaliação com proposta de melhoria do processo industrial da reciclagem de chumbo e indicação de aplicabilidade para a escória gerada. Curitiba. 2005. Dissertação de mestrado - Universidade Federal do Paraná, 2005.

12. LÃ, O.R., BARRA, C.M., SOBRINHO, N.M.B.do A., MAZUR, N., VELLOSA, A.C.X. Avaliação dos métodos de extração sequencial de Tessier, Keller e Miller na determinação de ferro nativo cem três tipos de solos: Orgânico, Brunizem e Latossolo. Química Nova, v.26, n.3, p.323-330, 2003.

13. LOS, F.J., COSTA, W., CHAVES, A.V., RIBICKI, A.C. Avaliação da presença e lixiviação de metais tóxicos em amostras de três marcas comerciais de alginatos. Revista Tecno-Lógica, v.17, n.1, p.38-43, 2013.

14. MACHADO, I. P., Avaliação Ambiental do Processo de Reciclagem de Chumbo. Campinas, 2002. Dissertação de mestrado - Unicamp, 2002.

15. MATTE, T. D., FIGUeROA, J. P., BURR, G., FLECH; EROME, P., KEENLYSIDE, R. A., BAKER, E. Z. Lead exposure among lead-acid battery workers in Jamaica. American Journal of Industrial Medicine, v.16, p.167-177, 1989.

16. MINOZZO, R., MINOZZO, E. L., DEIMLING, L. I., SANTOS-MELO, R. Plumbemia em trabalhadores da industria de reciclagem de baterias automotives da Grande Porto Alegre, RS. J. Bras. Patol. Med. Lab. v.44, n.6, p.407-412, 2008.

17. PAOLIELLO, M. M. B., CHASIN, A. A. M. Ecotoxicologia do chumbo e seus compostos. Salvador, CRA, 2001. 144p. (Cadernos de Referência Ambiental, 3)

18. SILVA, B.C.E. Balanço Mineral Brasileiro, Departamento Nacional de Produção Mineral DNPM,2001.Disponível em http://www.dnpm.gov.br/assets/galeriadocumento/balancomi neral2001/chumbo.pdf . Acesso em: 10.10.2010.

19. TESSIER, A., CAMPBELL, P. G. C., BISSON, M. Sequential extraction procedure for the speciation of particulate trace metals. Anal.chem. v.51 p.844-851, 1979. 